\title{
O AMERICAN DREAM E A CULTURA DAS APARÊNCIAS EM LITTLE CAESAR, DE MERYVN LEROY
}

\author{
Elder Kôei Itikawa Tanaka \\ Universidade de São Paulo \\ São Paulo, SP, Brasil
}

\section{Resumo}

Considerado o precursor dos filmes sonoros de gângster do chamado período "clássico" desse gênero, Little Caesar, dirigido por Mervyn LeRoy em 1931, narra o percurso do protagonista Rico Bandello (Edward G. Robinson) da sua ascensão à liderança da gangue à sua queda no final do filme. Little Caesar, além de estabelecer os parâmetros seguidos pelas narrativas dos filmes de gângster a partir dos anos 1930, também contribuiu para que o gângster se tornasse um ícone da cultura norte-americana graças à disseminação de sua figura por meio da indústria cultural, principalmente no cinema. Nosso objetivo com o presente trabalho é, por meio da análise de algumas cenas do filme, verificar de que maneira se configuram a cultura das aparências e a ideologia do American Dream ao longo da narrativa.

Palavras-chave: American Dream; Little Caesar; Cinema Norte-americano; Crime organizado; Gângster

\section{THE AMERICAN DREAM AND THE CULTURE OF APPEARANCES IN MERVYN LEROY'S LITTLE CAESAR}

\begin{abstract}
Known as the precursor of the gangster sound films from this genre's "classic" period, Little Caesar, directed by Mervyn LeRoy in 1931, narrates Rico Bandello's (Edward G. Robinson) path from his rise as a gang leader to his death. Little Caesar established the parameters followed by the gangster films in the 1930s and also contributed to the image of the gangster as an American icon due to its dissemination through the cultural industry, mainly in terms of films. My objective with this present article is to verify through the analysis of some of the scenes how the culture of appearances and the ideology of the American Dream are configured throughout the narrative.

Keywords: American Dream; Little Caesar; American Cinema; Organized Crime; Gangster
\end{abstract}

\section{Introdução}

Dentro da historiografia do cinema norteamericano, Little Caesar (Mervyn LeRoy, 1931) ocupa um lugar de destaque por diversos motivos. Em primeiro lugar, por ser o precursor do gênero gângster dentro do cinema falado, tecnologia que havia sido introduzida nos cinemas em 1927. Embora houvesse narrativas sobre o crime organizado no cinema mudo, nenhum dos filmes de gângster produzidos antes da década de 1930 teve o impacto que a obra dirigida por Mervyn LeRoy provocou nos espectadores da época. Para a crítica Fran Mason, a adição do som foi determinante para a evolução dos filmes de gângster, pois

os sons diegéticos da linguagem do gângster, tiros e o derrapar dos pneus, assim como os ruídos característicos do ambiente urbano,

\footnotetext{
* Doutor em Letras (2016) na área de Literatura e Cinema Norte-Americano pela Universidade de São Paulo (USP), Mestre em Letras na área de Literatura e Cinema Norte-Americano pela Universidade de São Paulo (2011). Tem experiência na área de cultura, atuando principalmente nos seguintes temas: literatura e cinema norte-americanos, história de Hollywood, censura no cinema hollywoodiano. Seu endereço de email é elder.tanaka@gmail.com.
} 
evocavam de modo mais eloquente o mundo moderno habitado pelo gângster do que as favelas escuras do gângster do cinema mudo. (...) Filmes mudos tinham armas, mas não conseguiam representar efetivamente o poder ou a ameaça do gângster porque eles só podiam mostrar que um tiro havia sido dado com a imagem da fumaça saindo do cano de uma arma. $^{1}$ (MASON, 2002, p. 4)

Em outras palavras, o advento do som no cinema possibilitou ao espectador dos filmes de gângster uma relação sensorial com o universo do crime que não era possível no cinema mudo.

Em segundo lugar, por ser considerado o primeiro grande filme de gângster desse período, Little Caesar contribuiu de maneira decisiva para a popularização da figura desse tipo de criminoso, associando-o no imaginário coletivo a grupos de imigrantes judeus, irlandeses, africanos, asiáticos e, principalmente, italianos. (GARDAPHE, 2010, p. 111) Tal associação ocorreu pela ascendência tanto dos personagens como dos atores, cujos modos de fala característicos ganharam evidência com a sincronização de som e imagem na tela do cinema.

Finalmente, Little Caesar tem importância histórica por configurar uma etapa importante no processo de representação dos trabalhadores dentro da indústria cinematográfica norte-americana após a Quebra da Bolsa de Nova York em 1929. Ou seja, no momento em que os Estados Unidos da América (EUA) passavam pela pior crise econômica enfrentada pelo país, o filme de gângster cumpre uma função dialética, pois permite que o trabalhador se veja em cena - por meio de atores com quem compartilha ascendências e modos de fala - ao mesmo tempo em que acompanha uma narrativa que criminaliza sua própria classe social em meio à Depressão. Dentro dessa perspectiva, o filme de gângster produzido nesse período configura uma tentativa de construir uma representação cultural da classe trabalhadora organizada, qualificando-a como "gangue", no sentido de "associação de malfeitores".

Todavia, a análise mais detida da narrativa de Little Caesar nos mostra que ela não se resume à criminalização do trabalhador. Além de abordar temas como a crise econômica nos anos 1930, o filme estabelece homologias estruturais entre o crime organizado e o mundo dos negócios. Tais questões surgem na narrativa por força da matéria histórica envolvida nas condições de produção.

Pode-se dizer que Little Caesar inaugura um ciclo de filmes em que a classe trabalhadora nos Estados Unidos é protagonista em Hollywood, ao mesmo tempo em que é associada ao crime organizado. Em vez de se organizar como classe e buscar uma saída mais produtiva coletivamente, os proletários em Little Caesar optam por enfrentar a Depressão através do crime, e passam a utilizar métodos burgueses para chegar ao poder. Nesse contexto, o filme apresenta simultaneamente diversos materiais - como o American Dream e a cultura das aparências - que dão à narrativa um enorme potencial crítico. Nosso objetivo com esse artigo é, por meio da análise de algumas das cenas de Little Caesar, demonstrar de que maneira esses temas são aproveitados no filme.

\section{O American Dream e a indústria cultural}

Baseado no romance homônimo que William Burnett escreveu inspirado na biografia de Al Capone, Little Caesar tem a direção de Mervyn LeRoy, que trabalhou como diretor em Hollywood até a década de 1960. O filme narra o percurso do protagonista Rico Bandello (interpretado por Edward G. Robinson) desde sua ascensão à liderança da gangue durante a Lei Seca - que proibiu a produção e venda de bebidas alcoólicas de 1920 a 1933 nos Estados Unidos - até sua queda no final do filme. Joe Massara (interpretado por Douglas Fairbanks Jr.) é o parceiro de Rico no início do filme, mas entra em conflito com o protagonista ao longo da narrativa, pois quer sair da vida de crimes - o que de fato realiza, mas sem conseguir se livrar das relações com o crime organizado.

Rico e Joe são apresentados ao espectador no início da narrativa em uma cena dentro de um pequeno restaurante. Rico é baixo, carrancudo e fala de maneira ríspida, com um linguajar cheio de gírias. Joe, por sua vez, é alto, esguio e de linguajar mais calmo. Após assaltarem um posto de gasolina, os dois se sentam ao balcão do restaurante e, enquanto aguardam a comida, leem uma notícia de jornal sobre "Diamond" Pete 
Montana (Ralph Ince), um grande gângster que receberá uma homenagem de seus subordinados. Rico lê a notícia e a câmera o focaliza em close enquanto diz para Joe:

Rico: Muita. "Diamond" Pete Montana. Ele não perde tempo com postos de gasolina. Ele é alguém. Ele está na cidade grande, fazendo coisas grandes. E olhe pra gente, dois pobres coitados, nada.

Joe: [em um plano mais aberto] É isso que você quer, Rico? Uma festa dessas para você? [Joe olha para cima, imaginando uma manchete de jornal] "Caesar Enrico Bandello, homenageado pelos seus amigos".

Rico: [Em plano americano, mostrando ambos os personagens] Eu poderia fazer tudo o que esse sujeito faz, e muito mais. Só que eu nunca tive a minha chance. Não tenho medo de nada. Quando estou numa encrenca, saio dela aos tiros. Quando eu chegar lá, será do meu jeito. Atiro primeiro, pergunto depois. Esse jogo não é para gente fraca. ${ }^{2}$

Joe, por sua vez, declara que só quer dinheiro para ter roupas caras, mulheres e depois abandonar a vida de bandido. Nesse momento, Rico é focalizado em close novamente:

Joe: [em voz-over] Quero voltar a dançar, como eu costumava fazer antes de te encontrar. Não sei, não fui feito para esse tipo de coisa. Dançar. Isso é o que eu quero fazer.

Rico: [com olhar incrédulo] Dançar? Mulheres? E aonde isso tudo vai te levar? Não quero saber de dançar. Quero fazer os outros dançarem. Joe: Bom, eu não me esqueci do dinheiro. Rico: Dinheiro é bom, mas não é tudo. Quero ser alguém na vida. [olhando para fora do enquadramento enquanto gesticula com uma faca na mão] Olhar bem fundo para um bando e saber que eles fariam o que eu quisesse. Do meu jeito ou nada. Ser alguém na vida. ${ }^{3}$

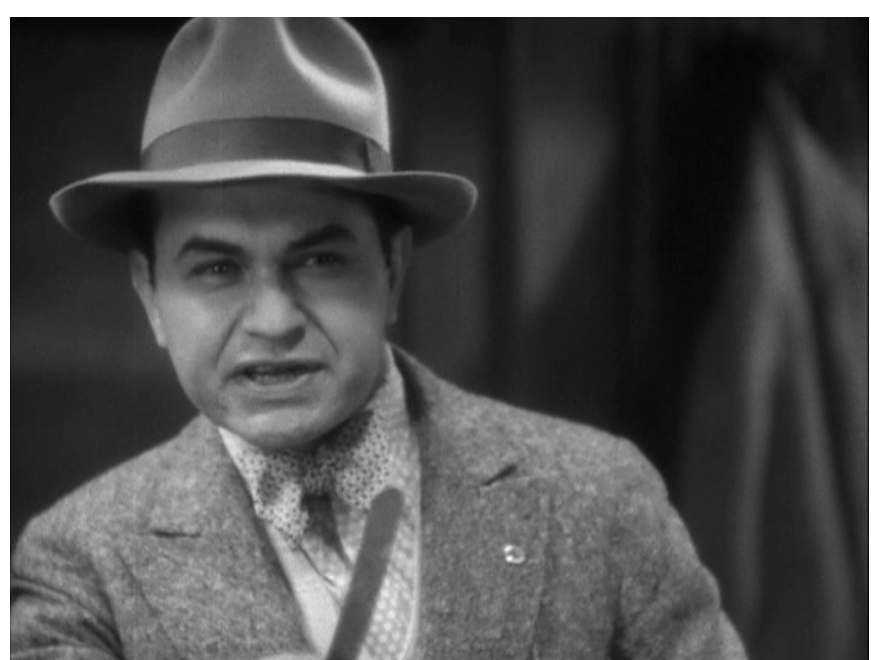

Figura 1 - Rico gesticula com uma faca na mão.

A sequência do diálogo entre Joe e Rico no restaurante apresenta ao espectador características importantes sobre os dois personagens que ajudam a compreender suas ações ao longo da narrativa. Fisicamente, Rico compensa sua baixa estatura com trejeitos enérgicos e ríspidos; o gângster é caracterizado como um sujeito carrancudo, e a tensão na sua expressão facial só é amenizada em poucos momentos do filme - quando o gângster sorri para a foto do jornal, ou quando se alegra ao receber de Big Boy (Sidney Blackmer) a notícia de que ocupará o lugar de Pete Montana, por exemplo. Ele é extremamente preocupado com sua própria imagem: as roupas de tecido barato dessa cena de apresentação evoluem de acordo com a ascensão de Rico na hierarquia da gangue; além disso, o protagonista está constantemente penteando o cabelo e adquirindo adornos para a sua aparência, principalmente joias, imitando os acessórios utilizados pelos seus superiores. Rico é prático, inteligente e rápido nas palavras. Apesar de ser o protagonista, não é construído de maneira a provocar no espectador uma adesão emocional, ao menos não da forma tradicional dramática, pois, além de fazer de tudo para impedir o romance entre Joe e Olga (Glenda Farrell), o gângster é antipático, grosseiro, e impõe respeito aos outros personagens por meio do medo.

Joe, por sua vez, personifica um contraponto visual ao protagonista: o amigo de Rico é um dançarino alto e esbelto, cuja fala e trejeitos são bem mais suaves e comedidos que seu parceiro. Mesmo tendo participado 
de um latrocínio na cena anterior, Joe ganha a simpatia do espectador na primeira vez em que surge na tela, por demonstrar o desejo de abandonar a vida de crimes. O diálogo inicial entre os dois personagens mostra ao espectador que, quando se trata dos objetivos a serem alcançados, Joe também quer dinheiro, mas para comprar roupas, conquistar mulheres e, em seguida, abandonar a vida de criminoso - a ordem em que Joe enumera seus desejos mostra que, a princípio, ele não se importa com a ilegalidade de suas ações para, posteriormente, atingir um objetivo "nobre".

Um dos pontos que mais chamam nossa atenção na apresentação dos dois personagens é a caracterização de Rico como um personagem que concentra em si a noção de empreendedorismo no mundo dos negócios ilegais. O objetivo do protagonista é "ser alguém na vida", e o personagem dá a entender que fará tudo o que for necessário para conseguir o que quer. Dessa forma, "apesar de todo o tiroteio, violência deliberada e onipresença da morte, o filme de gângster do início dos anos 1930 servia primordialmente como uma história de sucesso" (BERGMAN, 1992, p. 6).

Vale ressaltar que tanto o modus operandi do gângster no cinema como o fato da narrativa tê-lo como protagonista reforça, por meio da indústria cultural, o mito do sucesso individual na sociedade norte-americana. Sobre esse aspecto, o historiador Gerald Messadié aponta o ensaísta norte-americano Ralph Waldo Emerson como grande arauto. Segundo Messadié, Emerson

reforçou de modo singular a aspiração americana à liberdade total de ação: para o americano de então, assim como para os seus descendentes de hoje, o homem está só diante de Deus e, no fundo, só tem a obrigação de prestar contas a Ele. Pode-se imaginar o que um semelhante postulado implicou em termos de violência nas relações sociais e o quanto essa negação do contrato social resultou numa associabilidade que chega a beirar a anarquia. (MESSADIÉ, 1989, p. 32-33)

O sucesso individual e a mobilidade social, mesmo no período pós-crise de 1929, estavam no âmago do que os norte-americanos consideram como o American
Dream - um dos temas mais recorrentes no cinema norteamericano e, segundo Messadié, fonte do sentimento de superioridade dos EUA perante outras nações:
O sonho americano esteve presente desde o estabelecimento dos primeiros colonos: cada um viveria numa liberdade bíblica e se entregaria afinal, sem entraves - o que subentendia os entraves da sociedade decadente, papista e corrompida do Velho Continente -, aos seus afazeres terrenos. Assim, contribuiriam para a edificação de uma grande nação, cujo exemplo conquistaria todas as demais. Pode-se comparar esse evento à instalação dos judeus na Terra Prometida. [...] O Sonho Americano, assim, tinha também a marca de um sentido de predestinação que marcou fortemente a política americana a partir da Guerra da Independência, e lhe deu essa coloração arrogante que tanto surpreende os estrangeiros. (MESSADIÉ, 1989, p. 120)

Ainda de acordo com Messadié, é também a partir do American Dream que surge o "sentimento inato" dos indivíduos norte-americanos "de que tudo o que é americano é superior, simplesmente porque é americano, e, assim como o que é bom para a General Motors é bom para a América, o que é bom para a América é necessariamente bom para o resto do mundo" (MESSADIÉ, 1989, p. 120).

Segundo o historiador Jim Cullen, a formação do American Dream pode ser dividida em seis etapas. A primeira delas diz respeito aos imigrantes puritanos ingleses que, fugidos da perseguição religiosa que sofriam na Europa, atravessaram o Oceano Atlântico no século XVII em busca de uma "terra prometida" $\mathrm{e}$ colonizaram os EUA em nome da fé. A segunda etapa está ligada à Declaração de Independência dos EUA que, em 1776, institucionalizou como direitos inalienáveis dos cidadãos americanos "a Vida, a Liberdade e a busca da Felicidade". Segundo Cullen, "a busca da felicidade" define, melhor do que qualquer outra frase, "o American Dream ao tratar a felicidade como algo concreto e como um objetivo realizável" (CULLEN, 2003, p. 38).

A terceira etapa do American Dream está relacionada à crença na mobilidade social, ou seja, por meio do trabalho árduo qualquer um pode sair da 
pobreza e tornar-se "alguém na vida", como deseja Rico. Uma quarta etapa se desenvolve em torno do "sonho da igualdade", que pode se desdobrar em diversos tipos: igualdade política, igualdade civil, igualdade social e igualdade racial. (CULLEN, 2003, p. 105) A quinta etapa diz respeito ao "sonho da casa própria", que se institucionalizou em 1862 no Homestead Act assinado por Abraham Lincoln e culminou no desenvolvimento dos centros urbanos, dos subúrbios e no aumento da dependência do transporte por carros ao longo do século XX. Finalmente, a última etapa de formação do American Dream é definida por Cullen como o "sonho do litoral" (Dream of the Coast), e é geograficamente localizada na Califórnia, uma região do território dos EUA considerada, no imaginário do cidadão norteamericano, um lugar que une o clima agradável à possibilidade de enriquecer repentinamente e sem tanto esforço - seja na Corrida do Ouro no século XIX, nos cassinos de Las Vegas no século XX, ou em Hollywood, com a fama e fortuna de suas estrelas com carreiras meteóricas. (CULLEN, 2003, p. 133-184)

De todas as etapas descritas por Cullen, aquelas que estão mais diretamente relacionadas ao desejo de Rico de "ser alguém na vida" são o sonho da "mobilidade social" e da "busca pela felicidade". Entretanto, o que o filme nos apresenta - e o que constitui um de seus grandes potenciais críticos - é uma versão corrompida do American Dream, que não cabe no conceito mais incauto do sonho americano, mas que faz todo sentido dentro das condições de produção do filme. Little Caesar conta uma história, já na época de sua produção, "muito antiga na América. Rico pertence a uma nação que exige dele o sucesso individual e, em 1930, não oferecia as oportunidades de conquistá-lo legalmente" (BERGMAN, 1992, p. 9).

O grande veículo responsável pela ideologia do American Dream em Little Caesar é, como apontamos anteriormente, a indústria cultural, que se configura no filme de duas formas: nos espetáculos de dança e nas notícias de jornal mostradas ao longo da narrativa. A dança aparece no discurso de Joe tanto como desejo de retorno a uma atividade que ele praticava antes de encontrar Rico, como alternativa ao crime, simultaneamente legal e viável economicamente.
A escolha de Joe não é feita por acaso, pois a dança era uma forma de entretenimento muito popular no início do século XX, não só nos musicais da Broadway ou em salões de clubes com apresentações de jazz ao vivo, mas também na forma mais perversa das "maratonas de dança", que surgiram como forma de espetáculo ao longo da década de 1920 e ganharam força durante a Depressão. De acordo com a historiadora Carol J. Martin, essas maratonas podiam se estender por até doze semanas, mas os prêmios em torno de US\$ 1,500.00 atraíam centenas de competidores da classe trabalhadora, muitas vezes desempregados que viam nessas competições um modo de sobrevivência. Segundo Martin, as maratonas de dança

\begin{abstract}
parecem resumir o American Dream em uma de suas manifestações mais insanas e contraditórias. As maratonas mostravam coragem e esperança, determinação e estupidez, nonsense e decorações patrióticas, capacidade atlética e uma mistura incomum de números musicais, diversão honesta e piadas vulgares, meninos e meninas "de bem" e prostituição, resistência incansável e total esgotamento. (MARTIN, 1994, p. xv)
\end{abstract}

A dança também está relacionada ao próprio desenvolvimento técnico do cinema nesse período. A transição do cinema mudo para o falado provocou um aumento nos custos de produção e execução dos filmes, e elevou substancialmente os investimentos feitos por Wall Street em Hollywood. ${ }^{4}$ Assim, os estúdios se viram obrigados a explorar de maneira explícita a nova técnica a fim de justificar o dinheiro investido, e o musical passou a ser o principal gênero utilizado pela indústria como vitrine do avanço tecnológico. A maior prova disso foi a escolha desse gênero para a estreia da técnica com The Jazz Singer (Gordon Hollingshead, Alan Crosland, 1927).

Assim sendo, a análise da matéria histórica nos leva a acreditar que a escolha de Joe pela dança como alternativa para a vida criminosa visa a sua inserção numa indústria do espetáculo em pleno desenvolvimento. Se levarmos em conta que "Joe" é o nome inglês para o homem comum, ${ }^{5}$ também podemos dizer que a dança ocupa o espaço do desejo do personagem - a inserção no mundo do espetáculo é o sonho do Zé Ninguém. 
Além da dança, o jornal também é um elemento $\mathrm{da}$ indústria cultural que tem relevância para o enredo de Little Caesar. É por causa da manchete da homenagem a Pete Montana que Rico resolve tentar a vida em Chicago; quando Rico chega à liderança da gangue, sua fotografia é publicada na capa do jornal, do qual o gângster compra dez unidades para guardar de recordação; a expulsão de Arnie Lorch (Maurice Black), um dos inimigos de Rico, da cidade é consumada com uma nota na coluna social; finalmente, é por meio das declarações que dá aos jornais que o tenente Flaherty (Thomas E. Jackson) consegue provocar Rico e fazê-lo revelar seu esconderijo na sequência final do filme.

De fato, antes mesmo de ser figurado no cinema, o gângster já havia sido retratado tanto no jornalismo quanto na literatura. O próprio Al Capone admite ter lido livros sobre gângsteres, mas aponta uma ressalva importante:

Eu li um desses livros que estão no mercado agora, mas não tenho muito o que dizer a respeito. É bem escrito - até onde consegui perceber nas dez páginas do começo - mas é sobre outra pessoa. Esse livro diz tanto a meu respeito quanto um livro de Horatio Alger. ${ }^{6}$ (Apud RUTH, 1996, p. 118)

A declaração de Al Capone corrobora a tese do historiador David E. Ruth de que o gângster como o conhecemos na indústria cultural é, na verdade, uma invenção, "muito menos um reflexo preciso da realidade do que uma projeção criada a partir de várias crenças americanas, interesses e ideias sobre o que poderia se tornar rentável" (RUTH, 1996, p. 1). Segundo Ruth,

nos anos 1920 e início dos anos 1930, as inúmeras ofertas do gênero gângster estabeleceram o criminoso inventado como um dos símbolos da nova cultura de massa mais eminentemente poderosos e facilmente reconhecíveis. Os criadores do gângster deram a ele a tarefa de confrontar a sociedade urbana que ele representava. $O$ vocabulário simbólico do gênero era uma rica fonte cultural que jornalistas, cineastas, e outros usaram em tentativas de explicar e alterar o comportamento dos americanos que habitavam os centros urbanos. [...] Assim como qualquer outra invenção de sucesso, o gângster tinha uma utilidade. Embora fosse impossível medir a aceitação popular de mensagens específicas, o fato é que o gângster era uma mercadoria muito rentável. (RUTH 1996, p. 4)
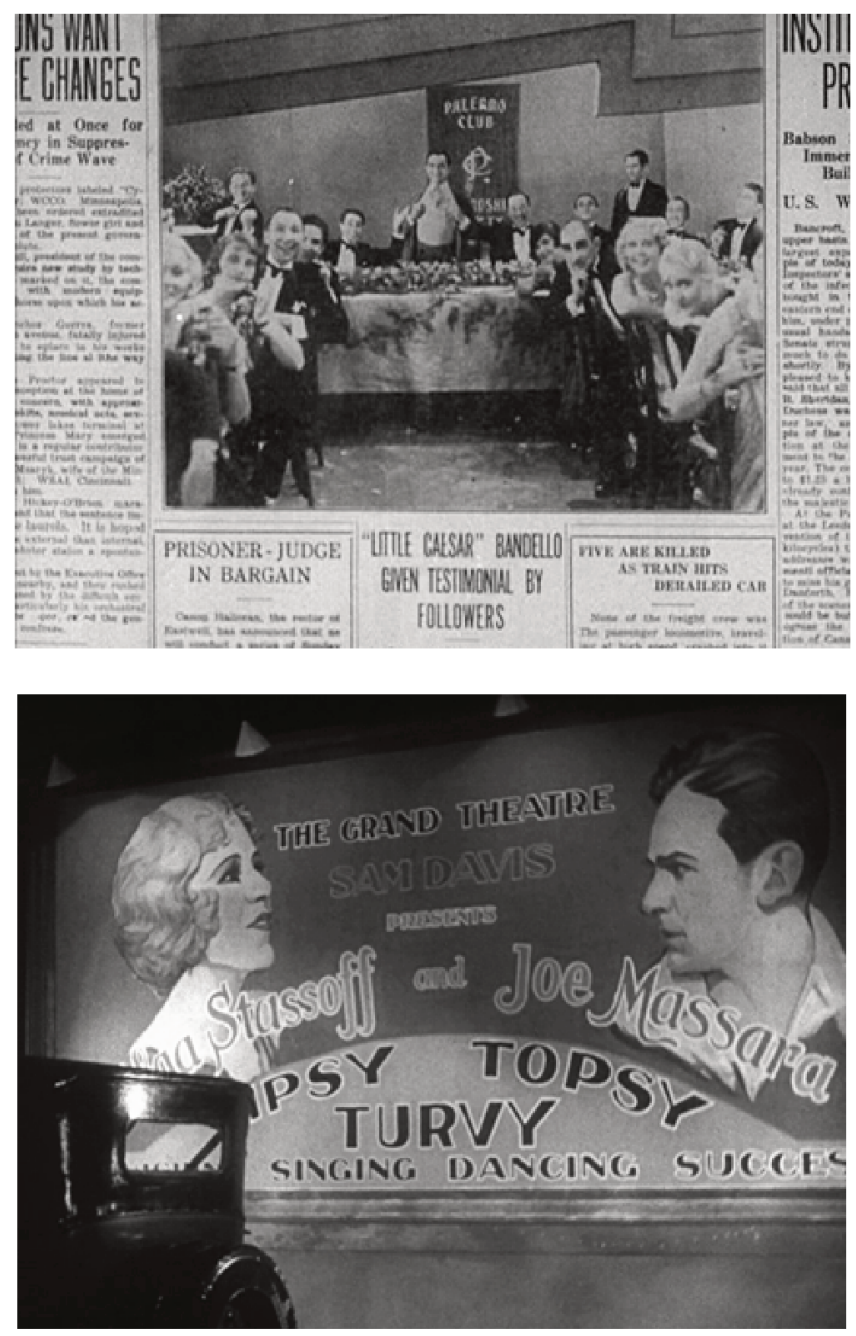

Figura 2 - Duas figurações da indústria cultural em Little Caesar: o jornal em close com destaque para a foto do banquete em homenagem a Rico (esq.) e o painel de anúncio do espetáculo com Olga e Joe na última cena do filme.

Dessa maneira, não interessava aos jornais ou a Hollywood se a figuração do gângster era próxima ou não da realidade, mas sim que ela chamava a atenção do público, o que gerava lucro:

A gangue é um negócio dentro do gênero [gângster], mas um tipo muito especial de negócio criado dentro da ficção Americana e em Hollywood. A estrutura corporativa 
da gangue, assim como o registro da vida do gângster em si, não corresponde ao gângster real e não são relevantes para o gênero ou à sua necessidade de verossimilhança, qualquer que seja o conceito de "real" utilizado. (KAMINSKY, 1972, p. 219)

A estratégia publicitária da indústria cultural, no entanto, era a de atestar a veracidade dos fatos, fossem eles as notícias de jornal ou os filmes. Um bom indício dessa estratégia pode ser visto no texto divulgado pela Warner Bros. na ocasião do lançamento de Blondie Johnson (1933), de Ray Enright:

Quando historiadores sérios começarem a juntar as peças que formam os nossos tempos modernos, eles agradecerão particularmente a quatro pessoas: James Cagney, Edward G. Robinson, Paul Muni e Joan Blondell. Esses quatro atores, mais do que qualquer um, estão fornecendo às futuras gerações uma representação fiel dos maiores problemas de nosso tempo através do cinema. Esses futuros escritores podem chamar nossa época de era dos ladrões, os anos em que a juventude do mundo enlouqueceu, revoltada contra a lei e a disciplina, ou eles podem fazer referência à era dos gângsteres, quando as forças da lei sofreram um eclipse. Qualquer que seja o nome que derem, qualquer que seja a explicação, as representações mais fiéis de todo esse estranho fenômeno internacional serão fornecidas pelos então antigos rolos de filmes conhecidos pelos nomes de "The Public Enemy", "Little Caesar", "Scarface" e "Blondie Johnson". O valor atual desses filmes é de entretenimento, mas, para futuros historiadores, eles servirão como fontes de inestimável valor. (RUTH, 1996, p. 5)

Não podemos dizer que a previsão da Warner Bros. em 1933 estava totalmente equivocada, uma vez que a própria existência do presente trabalho corrobora parte de sua tese. Por outro lado, nosso objetivo como críticos é questionar a fidelidade na representação da realidade que os produtores de filmes como Little Caesar alegavam promover na década de 1930. Um dos pontos mais interessantes nessas produções é justamente o conflito entre a realidade da violência urbana no início do século XX nos EUA e o mecanismo da indústria cultural, que vendeu ao público consumidor da época um acúmulo de diversas camadas de ideologia sobre aquela realidade. Segundo Theodor Adorno, "o mundo inteiro é forçado a passar pelo crivo da indústria cultural" (2002, p. 15). Na avaliação do crítico alemão,

a velha experiência do espectador cinematográfico, para quem a rua lá de fora parece a continuação do espetáculo que acabou de ver - pois este quer precisamente reproduzir de modo exato o mundo percebido cotidianamente - tornou-se o critério da produção. Quanto mais densa e integral a duplicação dos objetos empíricos por parte de suas técnicas, tanto mais fácil fazer crer que o mundo de fora é o simples prolongamento daquele que se acaba de ver no cinema. (ADORNO, 2002, p. 15-16)

Em Little Caesar, a combinação da tentativa da indústria cultural de reproduzir o mundo percebido cotidianamente com a ideologia do American Dream faz a narrativa ser lacunar na ascensão do protagonista dentro do mundo dos negócios. Rico ascende ao poder quase como resultado de sua personalidade: ele é o mais forte, mais audacioso, mais corajoso e, portanto, mais apto dentro da lógica corporativa do crime organizado a assumir um papel de responsabilidade entre seus pares. Sob o ponto de vista dramático, contudo, a construção dessa ascensão é rápida e sem muitos obstáculos, o que é facilmente perceptível na discussão que Rico tem com Vettori (Stanley Fields) sobre a divisão dos lucros do roubo ao Bronze Peacock. Logo após serem interrogados pelo tenente Flaherty sobre a morte do comissário de polícia durante o assalto, Rico sai de seu esconderijo com os sacos de dinheiro na mão. $O$ gângster se dirige à mesa de Sam Vettori e começa a separar o dinheiro. $\mathrm{O}$ enquadramento em plano médio mostra Rico em pé à esquerda, e Vettori, sentado à mesa à direita:

Vettori: [esticando o braço em direção ao dinheiro] Deixe-me ver a cor do dinheiro.

Rico: Só um minuto, Sam. Eu tenho o meu próprio jeito de dividir a grana dessa vez. $\mathrm{E}$ você pode aceitar ou cair fora. Ninguém está te pedindo nada.

Vettori: [levanta-se da cadeira e levanta a voz]: Eu fui o chefe desse trabalho. E eu vou pegar a 
minha parte...

Rico: [em close, interrompendo Vettori e também levantando a voz] Como você chefiou esse trabalho? Ficando aqui sentado jogando paciência? Isso não vai ser mais assim, já chega! Já recebi ordens suas por muito tempo...

Vettori [novamente em plano médio]: Você vai continuar recebendo minhas ordens... Ou você vai dar o fora daqui tão rápido que...

Rico: Talvez não seja eu que dê o fora.

Vettori: Ah, é? Talvez os rapazes tenham algo a dizer sobre isso. [olhando para fora do enquadramento] E então? [há um corte para um plano geral que mostra o restante da gangue se abstendo de qualquer comentário. Novo corte para um plano americano de Vettori, que se senta à mesa, derrotado] Então é assim?

Rico: [em close] Isso mesmo. Você fala o que quer, mas não aguenta ouvir o que não quer. Acabou pra você. [corte para o plano médio inicial] E então?

Vettori: [resignado] Tudo bem por mim, Rico. ${ }^{7}$

A montagem dessa sequência - que alterna o plano médio de Rico e Vettori com um plano geral do ambiente mostrando o isolamento de Vettori dentro do grupo, seguido pela ação do personagem em se sentar atônito à mesa - configura visualmente a queda do antigo chefe da gangue e a imediata ascensão de Rico, sem que Vettori sequer de fato lute pela liderança do grupo. A princípio, a resignação do personagem causa no espectador certo estranhamento, e o filme segue sem explorar de maneira mais aprofundada esse ponto importante da narrativa.

Ainda que anteriormente o filme mostre algumas atitudes de insubordinação de Rico à liderança de Vettori, a rapidez na evolução do personagem - de capanga recém-aceito na gangue a líder soberano reitera a mensagem cara à sociedade burguesa norteamericana de que basta ao cidadão comum - mais especificamente, à classe trabalhadora - o "perfil de liderança” e "espírito empreendedor" para "ser alguém na vida". O filme nos mostra, no entanto, que a junção harmônica da representação fidedigna da realidade com o American Dream é impossível.

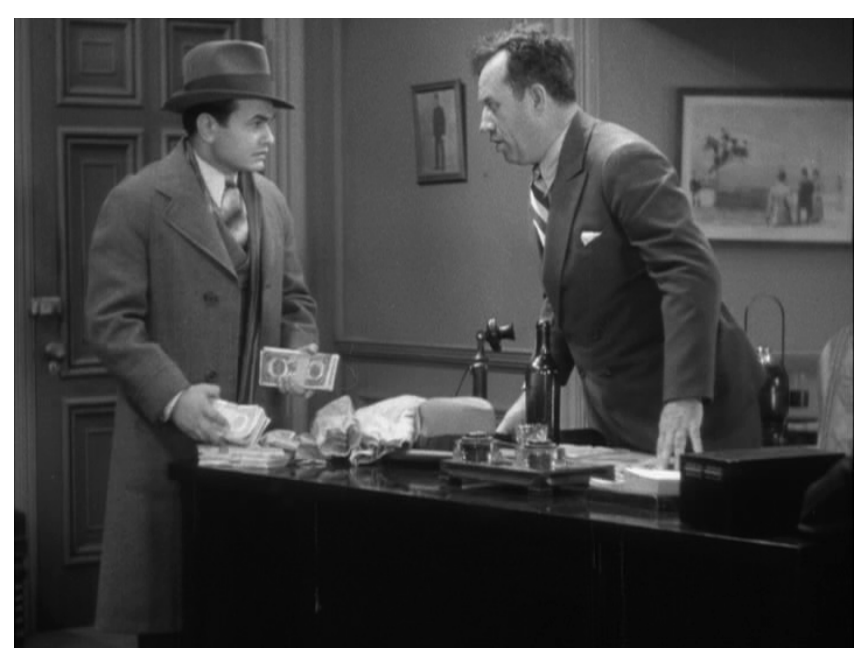

Figura 3 - Rico e Vettori discutem sobre a divisão os lucros

\section{Aparência e essência}

Um dos momentos mais emblemáticos do êxito alcançado por Rico em Little Caesar se dá no banquete em sua homenagem, oferecido por seus amigos e subordinados - assim como aquela homenagem oferecida a "Diamond" Pete Montana descrita pela manchete do jornal que o protagonista lê no início do filme. A sequência da festa tem início com um close de um cartaz com os dizeres: "Palermo Club - Amizade e Lealdade". Há um corte, e o plano seguinte registra Rico mostrando para Vettori, à sua esquerda, uma brochura comemorativa do banquete, com uma foto sua e mensagens de seus amigos. A mensagem que Vettori deixou é lida em voz alta por Rico: "Felicitações a um verdadeiro amigo, Sr. C. Bandello, de um verdadeiro amigo, Sr. Sam Vettori”.

No corte seguinte, o plano nos mostra, em dolly shot, da esquerda para a direita, as mesas com os convidados conversando e comendo. O enquadramento mostra Pete Montana à direita de Rico, e o restante de seus colegas de gangue à esquerda, ao lado de Vettori. Após o corte, um plano geral mostra o salão onde ocorre o banquete. Há uma algazarra generalizada entre os convidados, que falam alto, levantam-se da mesa e jogam pedaços de comida uns nos outros. Nesse momento, Vettori se levanta e grita, pedindo silêncio: "Qual o problema de vocês? Não sabem se comportar em um banquete? Parece um bando de vira-latas! Chega de papo. Scabby (Henry Sedley) vai fazer um discurso!"8. 
Há um corte e a câmera mostra Scabby, visivelmente embaraçado com a situação, se levantando. Os convidados aplaudem e festejam o discurso, e Scabby começa a falar:

Scabby: Bem, pessoal... vocês todos sabem por que estamos aqui, então não preciso ficar explicando, certo? O Rico é um grande sujeito!?

Todos aplaudem, e Rico aparece em close acenando e agradecendo os aplausos. A câmera volta para Scabby, que retoma o discurso:

Scabby: Sim, e... Bom... [sem saber como continuar, demonstrando desconforto] Olha, Rico, não sei falar bonito, mas [Scabby tira um relógio do bolso e mostra para Rico; há um corte para mostrar o relógio em close] esse relógio aqui é pra você. De todos nós! ${ }^{10}$

Ouve-se em voz-over o aplauso de todos, enquanto o relógio é entregue a Rico, que aparece em close outra vez, mostrando o presente orgulhosamente para os outros à sua volta. Os convidados, então, pedem que Rico faça um discurso. Ele reluta, mas se levanta, tira o guardanapo preso em seu colete e começa a falar:

Rico: OK, tudo bem... Vocês querem que eu faça um discurso, então aqui vai. Quero agradecer a todos vocês por esse banquete. Está ótimo. A bebida está boa, foi o que me disseram. Mas eu não bebo. $\mathrm{E}$ a comida também não deixa nada a desejar. Acho que estamos todos tendo uma ótima noite... E é bom ver vocês todos com suas garotas aqui. É, bem... [mostrando embaraço] Acho que é isso! [todos aplaudem, Rico se senta, mas torna a se levantar] Eu só gostaria que vocês não bebessem demais, porque é assim que muita gente acaba mal. [todos riem] ${ }^{11}$

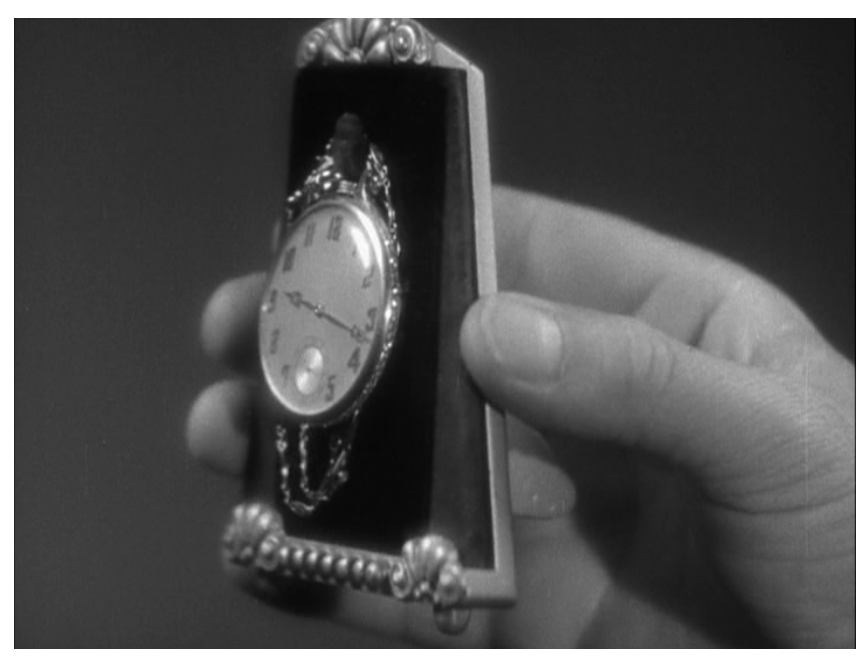

Figura 4 - O relógio que rico ganha de presente de seus amigos.

Nesse momento, um dos funcionários do Palermo Club aparece e avisa a Rico que os fotógrafos do jornal querem tirar uma foto. Rico manda os fotógrafos entrarem, tira um pente do bolso e começa a arrumar o cabelo. Nesse momento, Pete Montana se levanta e diz a Rico que volta depois, pois ele não deixa tirarem uma foto sua há quinze anos. Rico estranha o fato, mas deixa Pete sair. Os fotógrafos, então, entram no salão. Rico põe os polegares sob o colete e estufa o peito para a foto.

Assim que a foto é tirada, Pete Montana volta para o seu lugar e diz a Rico que aquela foto pode lhe causar problemas no futuro, ao que o protagonista prontamente responde: "Ora, qual o problema? Quero que as pessoas vejam o que os rapazes pensam de mim".

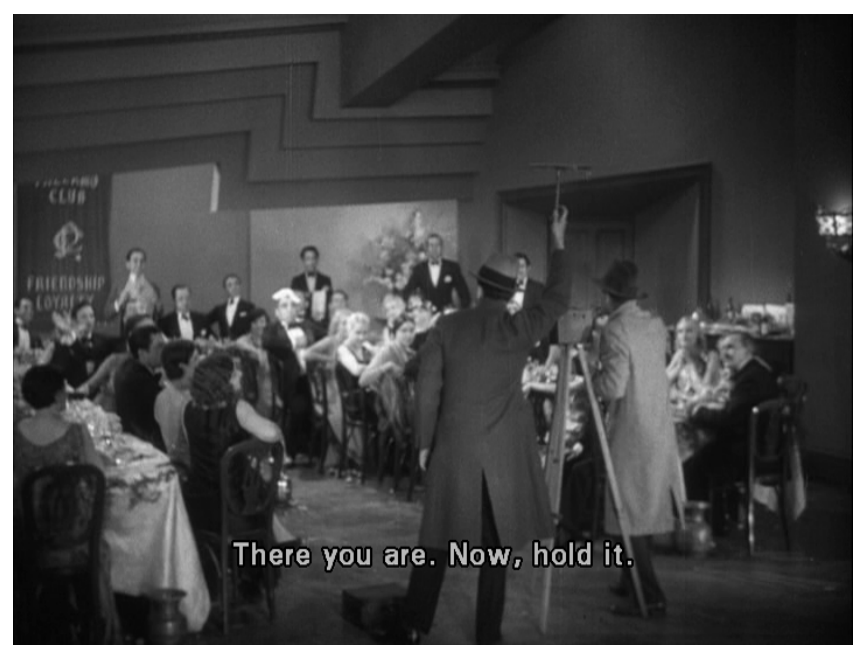

Figura 5 - Rico sendo fotografado durante o banquete em sua homenagem. 
Na sequência, o tenente Flaherty entra de surpresa no salão e diz a Rico em tom irônico que fica feliz por ele estar "subindo na vida", e aproveita para perguntarlhe se não sabe de nenhum relógio que havia sido roubado na noite anterior. Flaherty vai embora e Rico, ao descobrir a origem do relógio que ganhou minutos atrás, olha com reprovação para o restante da gangue.

Vários dos elementos dessa sequência - as homenagens por escrito na brochura, o relógio que Rico ganha de presente, os discursos e a fotografia para o jornal, além do banquete em si - materializam não só o acúmulo de poder e riqueza pelo protagonista, mas também sua sede de nomeada. Em outras palavras, não basta ao protagonista ter espírito empreendedor e conquistar sua independência financeira, é preciso criar uma imagem social vencedora e ser reconhecido pelos outros como uma pessoa de sucesso. Para Rico, mais do que ser um vencedor, é preciso parecer um vencedor.

O principal veículo pelo qual se dá o "prestígio imediato" das aparências de Rico é a indústria cultural, na figura do jornalismo. No dia seguinte ao banquete, $o$ protagonista pede ao jornaleiro dez cópias do jornal com sua foto na capa. O registro foto-jornalístico da festa é, em certa medida, mais importante para Rico do que o banquete em si, pois, além de divulgar em larga escala seus feitos, também legitima a ascensão do gângster à "alta sociedade", da qual ele desesperadamente quer fazer parte. Outro aspecto importante da foto de Rico no jornal é demonstrar como o criminoso - e o universo da ilegalidade em si - está totalmente integrado à sociedade legal. Segundo o teórico Ernest Mandel,

um filósofo produz ideias; um poeta, poemas; um sacerdote, sermões; um professor, compêndios; e assim por diante. Um criminoso produz crimes. Se olharmos mais de perto a relação entre esse último segmento e a sociedade como um todo, podemos nos livrar de muitos preconceitos. O criminoso produz não só crimes, mas também o código penal, o professor que dá aulas sobre direito criminal, e, finalmente, o inevitável compêndio no qual esse mesmo professor publica suas aulas no mercado editorial como "mercadorias". [...] O criminoso, além disso, produz toda a polícia e justiça criminal, policiais, juízes, executores, jurados, etc.; e todas essas diferentes linhas de negócios, que formam igualmente muitas categorias de divisão social do trabalho, desenvolvem diferentes capacidades do espírito humano, criam necessidades e novas formas de satisfazê-las. [...] O criminoso rompe a monotonia e a segurança do cotidiano da vida burguesa. Dessa maneira, ele impede que ela fique estagnada, e dá origem àquela tensão inquietante maior até do que o estímulo da competição. Assim, ele estimula as forças produtivas. Enquanto o crime tira uma parte supérflua da população do mercado de trabalho, e, dessa forma, reduz a competição entre os trabalhadores - prevenindo que os salários caiam abaixo do mínimo - a luta contra o crime absorve outra parte dessa população. Dessa forma, o criminoso funciona como um "contrapeso" natural, que traz equilíbrio e cria oportunidades para uma ampla gama de ocupações "úteis". (MANDEL, 1984, p. 10)

Mandel nos chama a atenção para a relação simbiótica entre o crime e o sistema produtivo. Se por um lado o crime depende do exército de reserva - gerado sobretudo em momentos de crise - para sobreviver, por outro lado certas ocupações dependem da ação criminosa. Em Little Caesar, por exemplo, podemos notar a quantidade de ocupações que surgem direta ou indiretamente do gangsterismo. Além dos policiais que perseguem a gangue ao longo do filme, também sobrevivem do crime organizado todos os trabalhadores envolvidos com o funcionamento dos clubes Palermo e Bronze Peacock (crupiês, garçons, balconistas, gerentes, dançarinos); os colunistas sociais, jornalistas e fotógrafos da imprensa local; o comércio de armas; os serviços funerários; os mordomos de grandes chefes como Big Boy, entre outros. Tais ocupações mostram ao espectador de Little Caesar que não existe um "submundo do crime"; pelo contrário, o gangsterismo é parte fundamental do sistema produtivo.

Dessa maneira, podemos dizer que o gangsterismo é uma atividade comercial plena, que cria empregos e faz o capital circular ao seu redor. Ao registrar o crime organizado não como exceção, mas como regra dentro do capitalismo, Little Caesar nos oferece um potencial crítico importante, pois revela um paradoxo: ao mesmo tempo em que pune o crime - que mantém o equilíbrio do sistema produtivo ao empregar tanta mão-de-obra 
-, a sociedade legal depende dele para que o exército de reserva gerado pela crise econômica não se organize coletivamente e reivindique mudanças no status quo.

Voltando à questão das aparências em Little Caesar, é possível notar no comportamento de Rico a percepção de que no palco da vida social não basta ter dinheiro, é preciso demonstrar que você o possui. É com essa finalidade que suas primeiras providências, assim que inicia sua trajetória dentro da gangue, se dão no âmbito do consumo: ternos caros, chapéus, sapatos, anéis de diamante, charutos, entre outros adornos, passam a fazer parte de seu vestuário.

O fascínio que Rico tem pelas aparências - e também pelas mercadorias - surge de maneira reiterada ao longo da narrativa através do close em diferentes objetos de valor, como o que ocorre com o relógio na sequência do banquete descrito anteriormente.
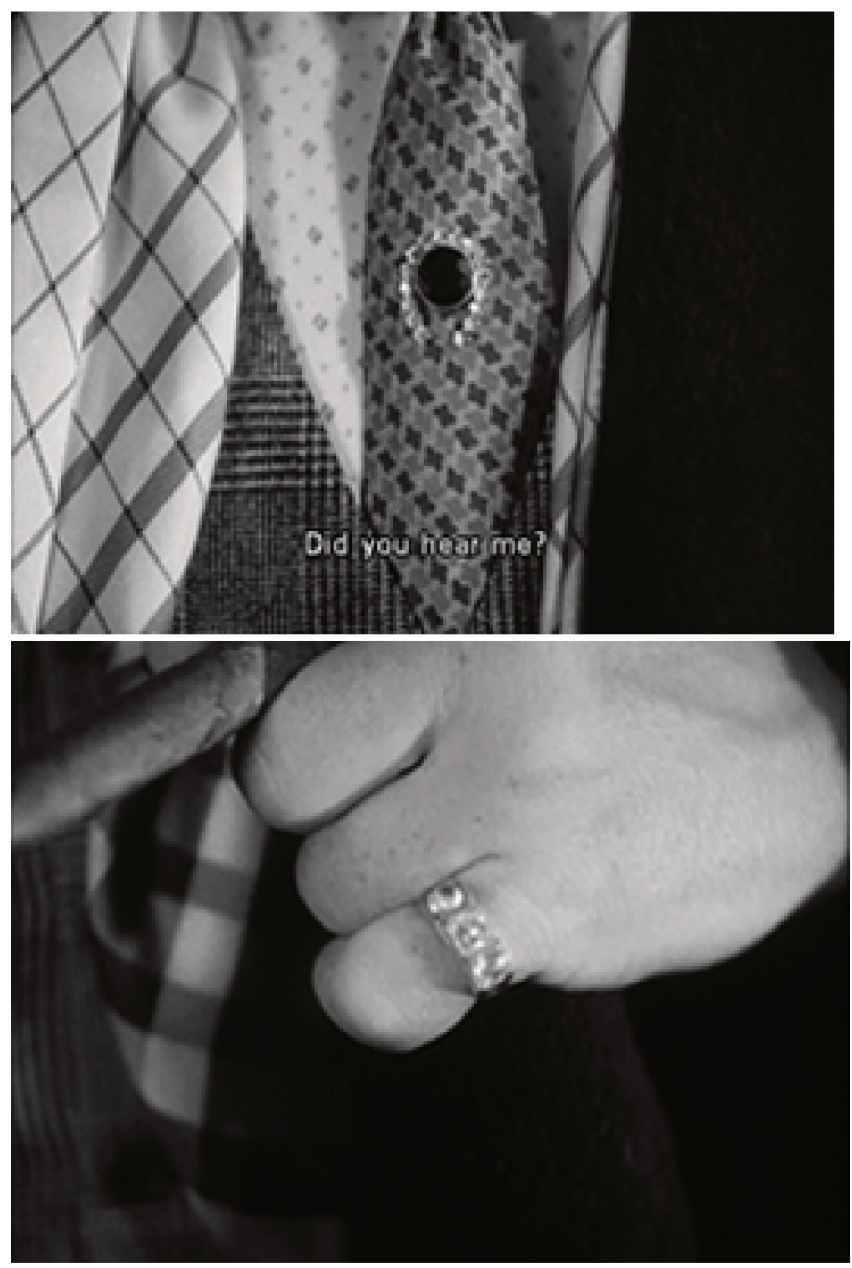

Figura 6 - Closes em diferentes mercadorias ao longo do filme.
Tal procedimento técnico enfatiza o fetiche de Rico por determinadas mercadorias que simbolizam seu avanço na hierarquia da gangue - por meio da montagem das cenas e da repetição da técnica, o espectador consegue relacionar ao protagonista todos os momentos em que esse recurso é utilizado.

Embora os closes nas mercadorias possam parecer, a princípio, um indício de que o filme segue o ponto de vista de Rico, o protagonista é utilizado em Little Caesar como objeto de observação. Não há no filme uma identificação formal, nem tampouco psicológica com Rico, porque ele é apresentado como um personagem antipático, feio, rude, que não conquista nossa adesão. Faz parte da intenção moralizante do filme que o gângster permaneça como objeto de observação a fim de que seja possível fazer um julgamento moral a cada instante. Ocorre que o distanciamento necessário para o julgamento moral também serve para o julgamento político. Dessa forma, mesmo sob o limite das convenções hollywoodianas, é possível captar questões impostas pela força da matéria histórica.

$\mathrm{O}$ auge do fascínio de Rico pelas aparências se dá na cena em que ele prova o terno que utilizará em seu primeiro encontro com Big Boy, o homem que controla todas as gangues de Chicago. O plano médio se mantém fixo do início ao fim da cena, mostrando Otero (George E. Stone), um dos integrantes da gangue, em primeiro plano à esquerda, e o reflexo do corpo inteiro de Rico à direita. O gângster está em pé sobre uma mesa ou um tablado. No início da cena, Otero aparece no espelho junto de Rico, ajeitando seu terno. O protagonista limpa o suor da testa e se sente visivelmente incomodado com a roupa:

Rico: Eu não sei... [Otero se afasta para observar Rico de longe, e aparece de frente para a câmera]

Otero: Você está ótimo, chefe!

Rico: É, mas eu me sinto péssimo! [ajeitando a roupa]

Otero: Oh, você está subindo na vida, Rico! Nenhum de nós já foi convidado para jantar na casa do Big Boy. E nunca ninguém entrou lá, a não ser Pete Montana. Entende o que eu estou dizendo? Você não quer que o Big Boy pense que você não tem classe.

Rico: [olhando para o espelho] Na prisão nos dão roupa melhor do que essa. [dirigindo-se a 
Otero] Se você acha que vou sair vestido desse jeito, está maluco. [começa a descer da mesa] Otero: [rapidamente] Você está ótimo, chefe! Vamos lá, dê uma bela olhada.

Rico: [subindo de volta para a mesa e resmungando] Ah, eu não sei. [olha-se no espelho] Só me falta um guardanapo no meu braço. [ajeita a gola da camisa]

Otero: [empolgado] E então? Não ficou bom?

Rico: [mexendo na roupa, com a fisionomia mais alegre] É, talvez eu não esteja tão mal assim. [Otero abre um largo sorriso] ${ }^{12}$

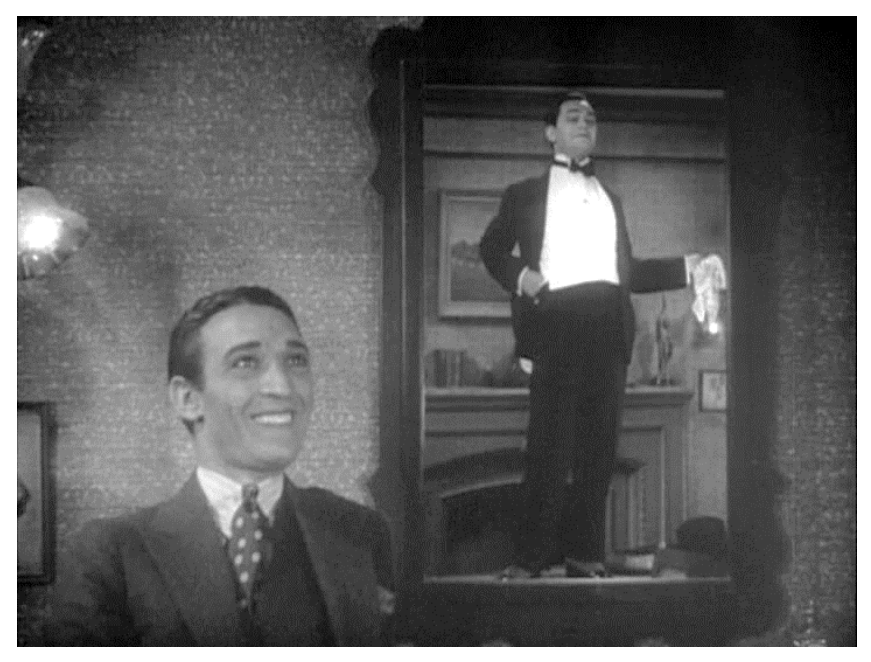

Figura 7 - Otero admira Rico provar seu terno.

É interessante notar o destaque que se dá nessa cena ao espelho, que ocupa praticamente metade do enquadramento; o reflexo - ou a aparência - de Rico é mais importante do que o gângster em si. A composição visual do quadro contribui para a sensação de restrição de movimentos do protagonista - além de Rico estar literalmente enquadrado na cena, ele reclama do desconforto da roupa e da sensação de ridículo ao se ver vestido daquela maneira. Curiosamente, no começo do filme, Rico explica a Joe que "quer ser alguém na vida" para poder fazer as coisas "do jeito dele ou nada". A cena da prova da roupa em Little Caesar, entretanto, nos mostra o quanto o protagonista é obrigado a se adaptar à roupa, e não o contrário. Se levarmos em conta que o sonho do gângster era ampliar seu campo de ação por meio da livre iniciativa, a composição visual dessa cena nos mostra, em primeiro lugar, a ironia da trajetória do protagonista, que se vê obrigado a se submeter às estruturas, códigos e rituais rígidos do convívio social burguês; e em segundo lugar, o processo de reificação do personagem, sua transformação em pura imagem. De acordo com Jameson,

a forma última da reificação mercantil na sociedade de consumo contemporânea é precisamente a própria imagem. Com essa mercantilização universal de nosso mundo objetivo, os conhecidos relatos sobre a direção-para-o-outro do consumo habitual contemporâneo e a sexualização de nossos objetos e atividades são também indícios: o novo carro da moda é essencialmente uma imagem que outras pessoas devem ter de nós e consumimos menos a coisa em si que sua ideia abstrata, aberta a todos os investimentos libidinais engenhosamente reunidos para nós pela propaganda. (JAMESON, 1995, p. 12)

Little Caesar nos mostra, entretanto, que a preocupação com a própria imagem não dissolve as lacunas culturais entre as classes sociais. Um bom exemplo se dá na sequência seguinte à prova de roupa, no primeiro e único encontro que Rico tem com o chefe das gangues da cidade. De acordo com Kaminsky, dentro da estrutura das gangues nos filmes de Hollywood,

os chefes permanecem acima da gangue, anônimos, à distância, e no controle. Quando os chefes são revelados, descobrimos que são da "alta sociedade", influentes e ricos. Eles podem ser desocupados ricos (Sydney Blackmer em Little Caesar), banqueiros e oficiais do governo (Bullets or Ballots) ou empresários de classe média de aparência respeitável (Jack Elam em Baby Face Nelson e Fred Clark em White Heat). São esses chefes da classe média e alta, escondidos atrás de um líder de gangue corajoso, que nós aprendemos a odiar nos filmes de gângster. Eles, em meio à Depressão que sabemos existir nos filmes dos anos 1930, estão acumulando riqueza, pegando o que há de dinheiro disponível, vestindo ternos, e vivendo do trabalho de gângsteres ambiciosos que surgiram da classe trabalhadora. Nós vemos o gângster assumir riscos, manter a gangue na linha, proteger sua posição, extorquir tributos de trabalhadores que não possuem o suficiente nem para si próprios, e, por fim, cair de maneira inevitável para ser substituído por outro como ele enquanto os chefes continuam protegidos. Esse padrão se repete a partir de 
Little Caesar, no qual o Big Boy não é nem preso, nem punido. (KAMINSKY, 1972, p. 220)

De fato, tanto Rico como o espectador só sabem da existência de Big Boy nas referências que se faz ao personagem durante a narrativa, e a presença dele em cena no filme é muito breve, o que reforça a afirmação de que sua posição dentro da hierarquia da gangue e na sociedade são quase inatingíveis para o protagonista.

Assim que entra na residência de Big Boy, Rico admira a arquitetura e a decoração do ambiente, até ver uma pintura na parede, que é mostrada em close enquanto Big Boy pergunta a Rico em voz-over:

Big Boy: Você gosta dela?

Rico: Oh, eu acho elegante.

Big Boy: [em close] Isso me custou quinze mil dólares.

Rico: [em close, demonstrando surpresa] Quinze mi- [olha para fora do enquadramento, na direção do quadro na parede] Cara, essas molduras de ouro devem custar mesmo uma fortuna. ${ }^{13}$

O comportamento individual de Rico na casa de Big Boy é análogo ao que ocorre coletivamente na cena do banquete, na qual nos

deparamos com uma simulação paródica de um banquete da alta sociedade. A gangue está vestida de maneira apropriada, mas não tem a menor noção do protocolo ou da linguagem adequadas a uma ocasião como essa. Ninguém consegue fazer um discurso eloquente, o banquete se desintegra em uma guerra de comida, e o presente que a gangue dá a Rico é roubado: aparentemente, aqueles que só conseguem macaquear a "sociedade", no fim das contas, são apenas macacos mesmo. (MUNBY 1999, p. 48)

Tanto a cena descrita acima como a do banquete em homenagem a Rico mostram o sentimento de vazio e de falta de sentido que o personagem experimenta conforme tem acesso aos fetiches que a sociedade burguesa lhe oferece em substituição aos seus desejos de classe. Faz parte da emancipação da classe trabalhadora o desejo de estar livre de qualquer necessidade ou restrição - não passar fome, por exemplo. Contudo, quando participa de um banquete, a sociedade burguesa oferece a Rico o consumo de mercadorias como a bebida alcoólica, da qual ele sequer pode tirar proveito porque não gosta de álcool, e a comida em abundância, que termina por ser arremessada pelos seus convidados entre si. O banquete em Little Caesar é uma figuração distorcida da saciedade, e a cena do quadro na casa de Big Boy reforça o caráter postiço da subjetividade burguesa assumida pelo protagonista ao longo da narrativa.

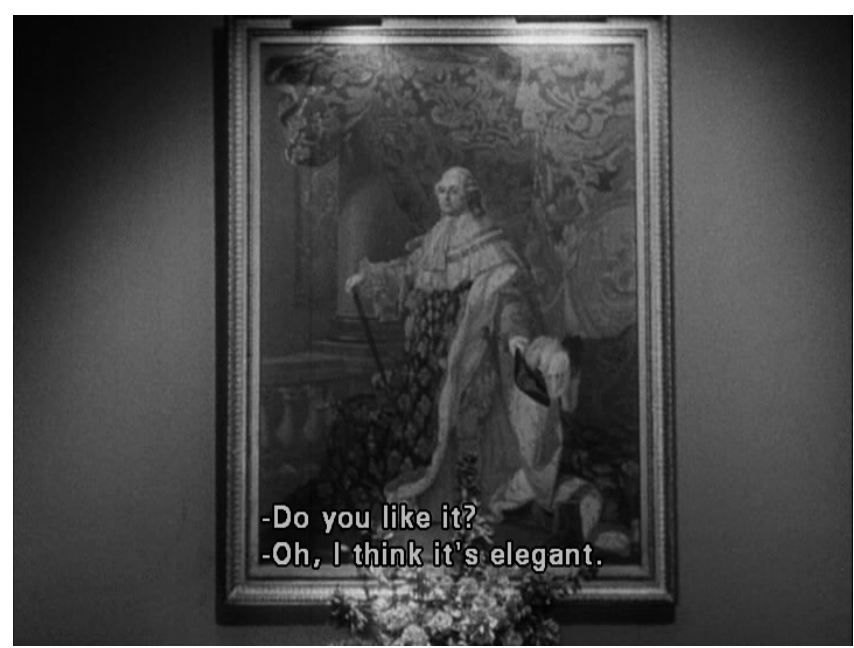

Figura 8 - A pintura na parede da casa de Big Boy.

O filme nos mostra que o gângster pode, por meio do crime organizado, comprar joias e roupas caras, e adquirir a aparência dos membros da alta sociedade; em sua essência, entretanto, o criminoso mantém a cultura de suas origens proletárias, que, dentro do julgamento efetuado pela narrativa, tem menor valor. O que o encaminhamento dessa questão ao longo da narrativa nos mostra é o estabelecimento de valores absolutos entre os polos, ou seja, a elite - mesmo que erigida ilegalmente - detém não só o poder econômico, mas também o cultural, enquanto Rico é considerado um indivíduo sem cultura. A cena de Rico com Big Boy em Little Caesar nos aponta, simultaneamente, a distância entre as classes sociais e a rigidez da estrutura que mantém essa distância. 


\section{Notas}

1. Todas as obras citadas neste trabalho que não possuem tradução oficial para o português são de autoria própria.

2. Rico: Plenty. "Diamond" Pete Montana. He don't have to waste his time on cheap gas stations. He's somebody. He's in the big town doing things in a big way. And look at us. Just a couple of nobodies, nothing.

Joe: Is that what you want, Rico? A party like that for you? "Caesar Enrico Bandello.

Honored by his friends."

Rico: I could do all the things that fella does and more. Only I never got my chance.

And what's there to be afraid of? When I get in a tight spot, I shoot my way out of it. Why, sure. Shoot first and argue afterwards. You know, this game ain't for guys that's soft.

3. Joe: I'd go back to dancing, like I used to before I met you. I don't know. I ain't made for this sort of thing. Dancing. That's what I wanna do.

Rico: Dancing? Women? And where do they get you? I don't want no dancing. I'm figuring on making other people dance.

Joe: Oh, I ain't forgetting about the money.

Rico: Money's okay, but it ain't everything. Be somebody. Look hard at a bunch of guys

and know they'll do anything you tell them. Have your own way or nothing. Be somebody.

4. O grupo de investimentos Goldman, Sachs \& Company financiou a compra dos estúdios Vitagraph e First National, além da rede de salas de cinema Stanley Theatres, pela Warner Bros.; o cabeamento do sistema sonoro das salas de cinema de todo o país e a construção de estúdios de som em Hollywood foram financiados em grande parte pelos grupos bancários Morgan e Rockefeller. (Cf. BALIO, 1993, p. 21-23.)

5. Common Joe e Average Joe são expressões em inglês usadas para denominar o sujeito americano comum, médio.

6. Horatio Alger (1832-1899) é conhecido no cenário da literatura infanto-juvenil norte-americana como um dos primeiros propagadores da ideologia do self-made man. Os protagonistas de seus romances eram garotos que saíam da miséria e alcançavam o "conforto da classe média" por meio da persistência e do trabalho árduo. (Cf. CLEMENT \& REINIER, 2011, p. 36).

7. Vettori: Let's see the color of that money.

Rico: Just a minute, Sam. I got my own ideas of a split. And you can take it or leave it. We ain't begging you.
Vettori: Yeah, well, I bossed this job... and I'm gonna get my split.

Rico: How'd you boss this job? By sitting here cheating at solitaire? Well, that don't go no more, not with me. We're done. I've been taking orders from you too long.

Vettori: You'll keep on taking orders too... or you'll get out of here so fast...

Rico: Maybe it won't be me that gets out.

Vettori: No? Well, maybe the boys have got something to say about that. What about it? So that's it, huh?

Rico: Yeah, that's it, all right. You can dish it out, but you're getting so you can't take it no more. You're through. Well?

Vettori: Well, the split's okay with me, Rico.

8. What's the matter with you birds? Don't you know how to act at a banquet? What do you think you are, a lot of gashouse yaps? Well, cut the chatter. Scabby's gonna make a speech.

9. Scabby: Well, folks... you all know what we're here for so what's the good of metelling you all about it? Rico here is a great guy!

10. Scabby: Sure, and, uh... Well... Say, Rico, I don't know how to talk fancy, but... This here watch is for you, see? From the boys!

11. Rico: Oh, well. All right. You birds want me to make a speech? Here it goes. I want to thank you, fellas, for this here banquet. It sure is swell. The liquor is good, so they tell me. But I don't drink it, myself. And the food don't leave nothing to be desired. Well, I guess we're all having a swell time... and it sure is good to see all you gents with your molls here. Yeah. Well, I... I guess that's about all. And I wish you birds wouldn't get drunk and raise Cain because that's the way a lot of birds get bumped off.

12. Rico: I don't know...

Otero: Ah, you look great, boss.

Rico: Yeah, but it feels terrible.

Otero: Aw. You're getting up in the world, Rico. None of us ever been invited up to eat at the Big Boy's dump. And nobody ever crashed the gate except Pete Montana. See what I mean? Now, you don't want the Big Boy to think you ain't got no class.

Rico: They rig you up better than this in the stir. If you think I'm going out in this, you're crazy!

Otero: You look fine, boss. Go on. Take a peek at yourself.

Rico: Oh, I don't know. All I need is a napkin over my arm. 
Otero: Now, don't you look fine? Hm?

Rico: Yeah. I guess maybe I don't look so bad after all.

13. Big Boy: Do you like it?

Rico: Oh, I think it's elegant.

Big Boy: That cost me $\$ 15,000$.

Rico: Fifteen thou- Boy, them gold frames sure cost plenty of dough.

Referências bibliográficas

ADORNO, T. "A indústria cultural - o Iluminismo como mistificação das massas”. In: Indústria cultural e sociedade. São Paulo: Paz e Terra, 2002. p. 7-74.

BALIO, T. Grand Design: Hollywood as a modern business enterprise, vol. 5, 1930-1939. New York: Simon \& Schuster Macmillian, 1993.

BERGMAN, A. We're in the Money: Depression America and its films. Chicago: Ivan R. Dee, 1992.

CUlleN, J. The American Dream: A short history of an idea that shaped a nation. New York: Oxford University Press, 2003.

CLEMENT, P. F. \& REINIER, J. S. (ed.). Boyhood in America: An Encyclopedia, Volume 1. Santa Barbara: ABC-Clio, 2011.

GARDAPHE, F. L. "Mafia stories and the American gangster". In: Nickerson, Catherine R. The Cambridge Companion to American Crime Fiction. Cambridge: Cambridge Univeristy Press, 2010. p. 110-120.

JAMESON, F. Marcas do visível. Rio de Janeiro: Graal, 1995.

KAMINSKY, S. M. "Little Caesar and its Role in the Gangster Film Genre”. In: Philadelphia: Journal of Popular Film, Vol. 1, Iss. 3, 1972. p. 209-227.

LITTLE Caesar. Direção: Mervyn LeRoy. Burbank: Warner Home Video, 2005. 1 DVD (78 min), NTSC, $\mathrm{P} \& \mathrm{~B}$.

MANDEL, E., Delightful Murder - A social history of the crime story. Minneapolis: Univeristy of Minnesota Press, 1984.

MARTIN, C. J. Dance Marathons: Performing American Culture of the 1920s and 1930s. Jackson: University Press of Mississippi, 1994.

MASON, F. American Gangster Cinema - from Little Caesar to Pulp Fiction. New York: Palgrave Macmillian, 2002.

MESSADIÉ, G. A crise do mito americano - Réquiem para o super-homem. São Paulo: Ática, 1989.
MUNBY, J. Public Enemies, Public Heroes - Screening the Gangster from Little Caesar to Touch of Evil. Chicago: The University of Chicago Press, 1999.

RUTH, D. E. Inventing the public enemy: the gangster in American culture, 1914-1934. Chicago: The University of Chicago Press, 1996.

Recebido em: 13/07/2016 Aceito em: 13/11/2016 